\title{
LINKING LAND USE CHANGES TO VARIATION IN SURFACE WATER QUALITY: EVIDENCE FROM 36 CATCHMENTS IN IRAN
}

\author{
MAHMOODI, M. ${ }^{1}-$ HONARMAND, M. ${ }^{1 *}-$ NASERI, F. ${ }^{1}-$ MOHAMMADI, S. ${ }^{1}$ \\ ${ }^{1}$ Department of Ecology, Institute of Science and Technology and Environmental Sciences, \\ Graduate University of Advanced Technology, Kerman, Iran \\ *Corresponding author \\ e-mail: mehonarmand167@yahoo.com
}

(Received $13^{\text {th }}$ Feb 2019; accepted 24 $4^{\text {th }}$ May 2019)

\begin{abstract}
In this article, the response of surface water quality to land use/land cover changes studied. We investigate the impact of land use changes on quality of water during three decades in the Razavi Khorasan Province of Iran. Detecting of LULC changes has done using Landsat satellite images belonging to the years 1987 (TM), $2001\left(\mathrm{ETM}^{+}\right)$and 2015 (OLI). In the study area based on RS and GIS standard techniques, sixteen land use classes were defined: barren, rocky, residential, swamp, water, dunes, salt marsh, irrigated cultivation, garden, dry farming, desert, good rangeland, medium rangeland, poor rangeland, wooded rangeland, and watercourse. Also, the water quality data from 1987 to 2015 in the stream gauge station located at the outlet of the 36 catchments analyzed. In this study, 13 parameters included $\mathrm{K}, \mathrm{Cl}, \mathrm{Ca}, \mathrm{Mg}, \mathrm{Na}, \mathrm{CO}_{3}, \mathrm{HCO}_{3}, \mathrm{SO}_{4}, \mathrm{EC}, \mathrm{pH}$, TDS, SAR, and Hardness investigated. After removing variance, non-parametric tests performed and trends of water quality variables in the time series evaluated. Then, using a multivariate linear regression model was trying to link water quality variables to land use changes. Results demonstrated that the models estimate water quality parameters with an acceptable degree of accuracy ( $\mathrm{P}$-value $<0.05$ ) except calcium, potassium, carbonate, and bicarbonate. The results showed the relationship between land use and the water quality indicators that can be applied in environmental protection and land use planning.
\end{abstract}

Keywords: sustainable development, remote sensing, regression model, Landsat satellite, GIS

\section{Introduction}

Ecological and human health directly affect by water attribute and for this reason, the quality of water is as important as its quantity (Zamani et al., 2013). In the past few decades, surface water characteristics deteriorated in numerous countries. The major environmental worry is the deterioration of stream water quality due to unsustainable activities of human (Chen and $\mathrm{Lu}, 2014$ ). Also, the quality of water is momentous to assess the health of a watershed and to make necessary management decisions to control current and future pollution (Walling and Fang, 2003). Water carries the particles from the land, as flows from the land surface and be enriched with different kinds of contaminants when flows from various types of land use (Tong, 1990). Rivers are vulnerable to land use and land cover (LULC) change and ubiquitous exploitation (Withers and Jarvie, 2008; Vörösmarty et al., 2010) and comprehending the relationship between land use and surface water quality is essential for effective water management (Ding et al., 2015).

Watershed is a topographic region of natural space that encompasses the correlation of water, its physical appearance, along with the related movement of elements connected with water resources usage. Thus, the best unit for water-related research at the regional scale is catchment (Li et al., 2012). The relevance between the quality of water in rivers and land use, despite its significance for the watershed, is not well described (Ding et al., 2016). Many studies derived that a significant relationship exists 
between the water quality parameters and land use and land cover at a basin scale (Kibena et al., 2014; du Plessis et al., 2014), while others demonstrated that are dependent on the depth of studies (Miserendino et al., 2011; Dabrowski et al., 2013; Namugize et al., 2018). Because of its reiterative data, digital format appropriate for processing, and precise geo-referencing approaches, satellite imagery is the most common data source for detection and mapping of land use changes (Minaei and Kainz, 2016). LULC change detection has become the main usage of RS data, due to repetitive coverage at short intervals and consistent image quality (Joorabian Shooshtari et al., 2012).

In relation to ecology, deforestation, desertification, urbanization, sustainable management of natural resources, identifying and modelling the impacts of weather events and climate change, etc land use change is monitored (Rafiee et al., 2009). Geographic Information System (GIS) provides many various methods to analyze and evaluate land use changes. These methods developed by using Remote Sensing (RS) and image processing techniques. For example, in the Beijing, (in China) (Wu et al., 2006) applied a combination of GIS and RS to find land use changes and found a significant increase in urban areas and a decline in rangeland from 1986 to 2001. Or in another research, in the north-western coastal region of Egypt from 1987 to 2001, (Shalaby and Tateishi, 2007) monitored land use changes used the post-classification method and maximum likelihood technique to generate the maps, detect land use changes and report on the effects of development projects in tourism and agriculture on vegetation cover region. In the west of Nile River (Egept), (Abd El-Kawy et al., 2011) applied Post-classification comparisons to investigate land use changes. And numerous similar studies conducted using GIS and RS combinations.

To specify whether the measured values of a variable increase or decrease during a period, generally trend analysis apply. Many methods are available for the quantification and detection of trends: regression analysis, T-tests, graphical methods, etc. Trend analysis method for water quality data should consider some of the specifications generally found in the water quality data (Zamani et al., 2013). Seasonality, non-normality, missing values, outliers, autocorrelation, and dependence on other variables such as river flow are some of these specifications (Zamani et al., 2013). (Esterby, 1996) provided a comprehensive review of statistical approaches that are using for trend analysis of water quality time series.

The intricate relationships of land use, water quality in various geographical regions under different scales are yet to be clarified, although there are some studies on the impacts of land use on water quality. The common procedures for predicting water quality in river basins based on land use types are still developmental. In a study, Huang explained the major participants to the increase of nutrients and sediments in freshwater ecosystems are increasing in agricultural and civil areas (Huang et al., 2016). Results in another study by (Mello et al., 2018), showed that organic matter and nitrogen were more influenced by the riparian zone composition, while fecal coliforms, phosphorus, sediment, and dissolved oxygen were affected by land use types at the watershed scale (Shi et al., 2017) in their research found that the land use composition in a riparian area is a superior predictor of water quality than in the whole basin, while (Zhou et al., 2012) showed that land use types at the basin scale can better account for the variability in river water quality.

Iran is among the arid and semi-arid countries of the world, and in most of its areas, there is a water shortage problem. Khorasan Razavi, besides the problem of water 
shortage, has a problem with reducing water quality. As it follows from the review of previous studies, one of the factors of long-term change in water quality is the change in land use. However, according to the authors' information, in Khorasan Razavi Province, no research has been undertaken for linking the spatial and temporal changes in land use and quality of water. The purpose of this study is to answer three basic questions. First of all, is land use change in Khorasan Razavi province significant? Second, do these land use changes affect the quality of surface water resources? And eventually, are these changes in water quality predictable and can be modelled?

\section{Material and methods}

\section{Study area and data description}

Razavi Khorasan province with an area of $117966 \mathrm{~km}^{2}$, located between $56^{\circ} 13^{\prime} 40^{\prime \prime}$ to $61^{\circ} 17^{\prime} 07^{\prime \prime}$ eastern longitudes and $33^{\circ} 51^{\prime} 16^{\prime \prime}$ to $37^{\circ} 42^{\prime} 18^{\prime \prime}$ north latitudes in the northeast of Iran (Fig. 1).

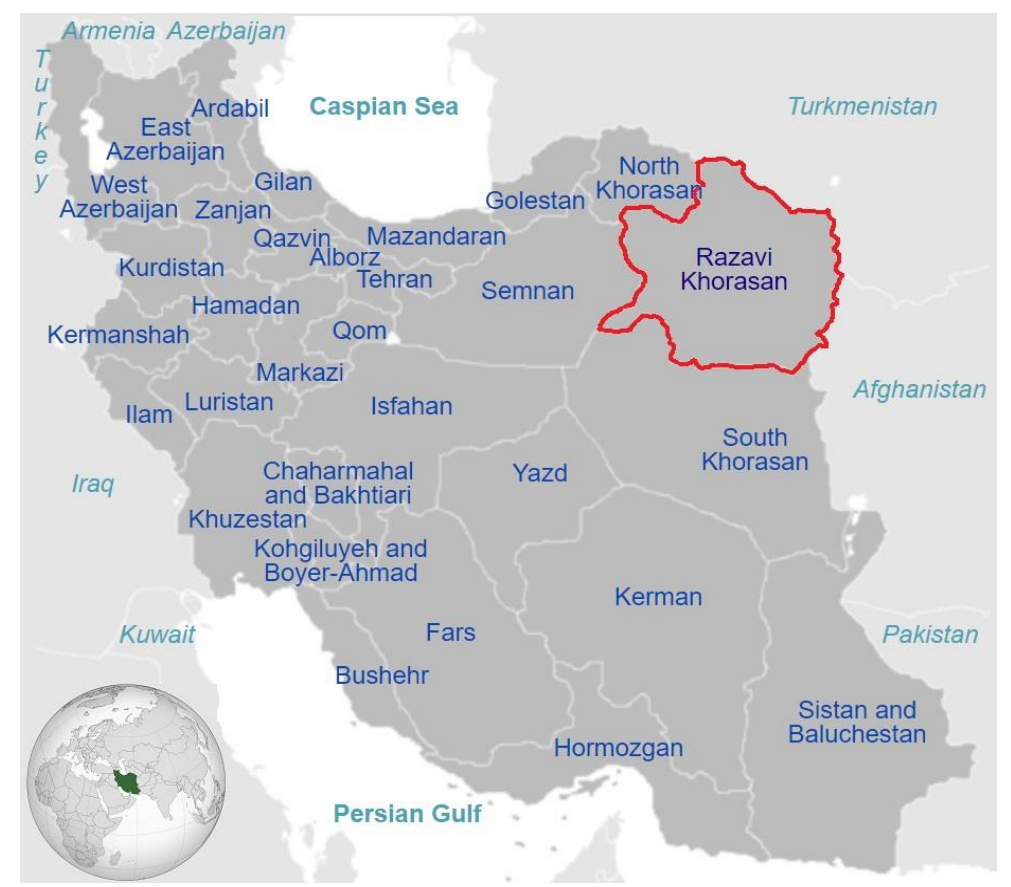

Figure 1. Geographical location of Razavi Khorasan Province in Iran

Two kinds of data applied in this research: land use data and water quality data. To study the dynamics of land use, it is needful to have maps that reflect the status of land cover at various periods. In this study, we used a set of Landsat satellite images from TM (1987), $\mathrm{ETM}^{+}$(2001) and OLI (2015) sensors to obtain land use maps of Khorasan Razavi Province. For complete coverage of the province in each year, 12 images (Overall 36) were used (Table 1). Figure 2 shows the final image of 1987, which is a combination of 12 Landsat 5 images. For the 2001 image, the combination of 12 Landsat 7 images and for the 2015 image, the combination of 12 Landsat 8 images used (Figs. 3 and 4, respectively). 
Table 1. Satellite images applied over the study period (each year 12 images, overall 36)

\begin{tabular}{c|c|c|c|c|c}
\hline \multicolumn{2}{c|}{ Number } & \multicolumn{3}{|c|}{ Date of frames } & \multirow{2}{*}{ Spatial resolution (m) } \\
\hline Row & Path & TM & ETM + & OLI & 30 \\
35 & 158 & $1987 / 06 / 27$ & $2001 / 07 / 11$ & $2015 / 06 / 24$ & 30 \\
36 & 158 & $1987 / 06 / 27$ & $2001 / 07 / 27$ & $2015 / 06 / 24$ & 30 \\
37 & 158 & $1987 / 06 / 27$ & $2001 / 06 / 25$ & $2015 / 06 / 24$ & 30 \\
34 & 159 & $1987 / 06 / 18$ & $2001 / 05 / 31$ & $2015 / 06 / 15$ & 30 \\
35 & 159 & $1987 / 06 / 18$ & $2001 / 05 / 31$ & $2015 / 06 / 15$ & 30 \\
36 & 159 & $1987 / 06 / 18$ & $2001 / 05 / 31$ & $2015 / 06 / 15$ & 30 \\
34 & 160 & $1987 / 06 / 25$ & $2001 / 07 / 09$ & $2015 / 06 / 22$ & 30 \\
35 & 160 & $1987 / 06 / 25$ & $2001 / 07 / 09$ & $2015 / 06 / 22$ & 30 \\
36 & 160 & $1987 / 06 / 25$ & $2001 / 06 / 23$ & $2015 / 06 / 22$ & 30 \\
34 & 161 & $1987 / 06 / 16$ & $2001 / 05 / 29$ & $2015 / 06 / 29$ & 30 \\
35 & 161 & $1987 / 06 / 16$ & $2001 / 06 / 30$ & $2015 / 06 / 29$ & 30 \\
36 & 161 & $1987 / 06 / 16$ & $2001 / 06 / 30$ & $2015 / 06 / 29$ & \\
\hline
\end{tabular}

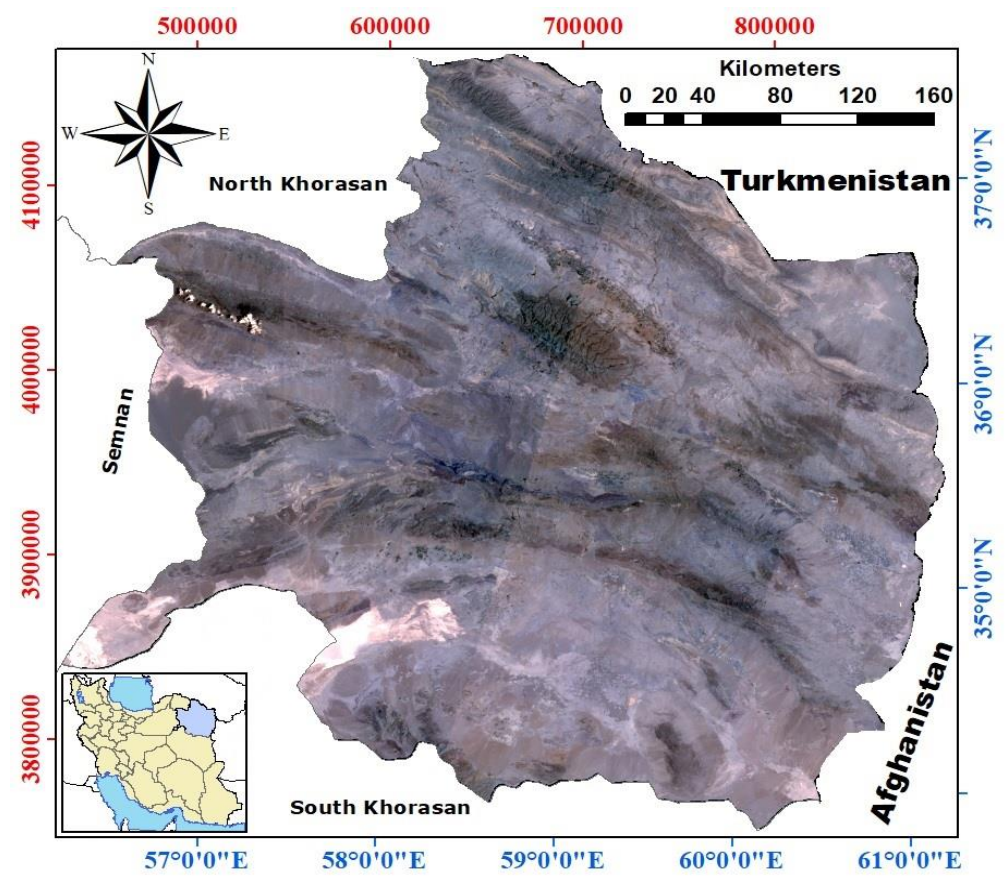

Figure 2. Image of 1987 (the result of combining 12 Landsat 5 images)

This study was performed to apply the river-basin based approach to analyze possible statistical and spatial correlations of LULC on the surface water quality. In this province, there are 70 hydrometric stations located at the outlet of the watersheds (Fig. 5). For this study, 36 stations with complete data of surface water quality in the years studied selected (Table 2). The water quality data for the period of 1987-2015 obtained from the Iran Water Resources Research Organization. This organization is a repository for water quality, quantity, chemical and physical data. Water quality variables, including calcium $(\mathrm{Ca})$, potassium $(\mathrm{K})$, chlorides $(\mathrm{Cl})$, carbonate $\left(\mathrm{CO}_{3}\right)$, bicarbonates $\left(\mathrm{HCO}_{3}\right)$, magnesium $(\mathrm{Mg})$, sulphate $\left(\mathrm{SO}_{4}\right)$, sodium $(\mathrm{Na})$, electrical 
conductivity (EC), potential of hydrogen $(\mathrm{pH})$, sodium adsorption ratio (SAR), total dissolved solids (TDS), and total hardness (TH) were chosen. The data is measured on these stations daily. Since the changes in water quality due to land use changes do not change over a day, therefore, the multi-day average of these data was used in this study.

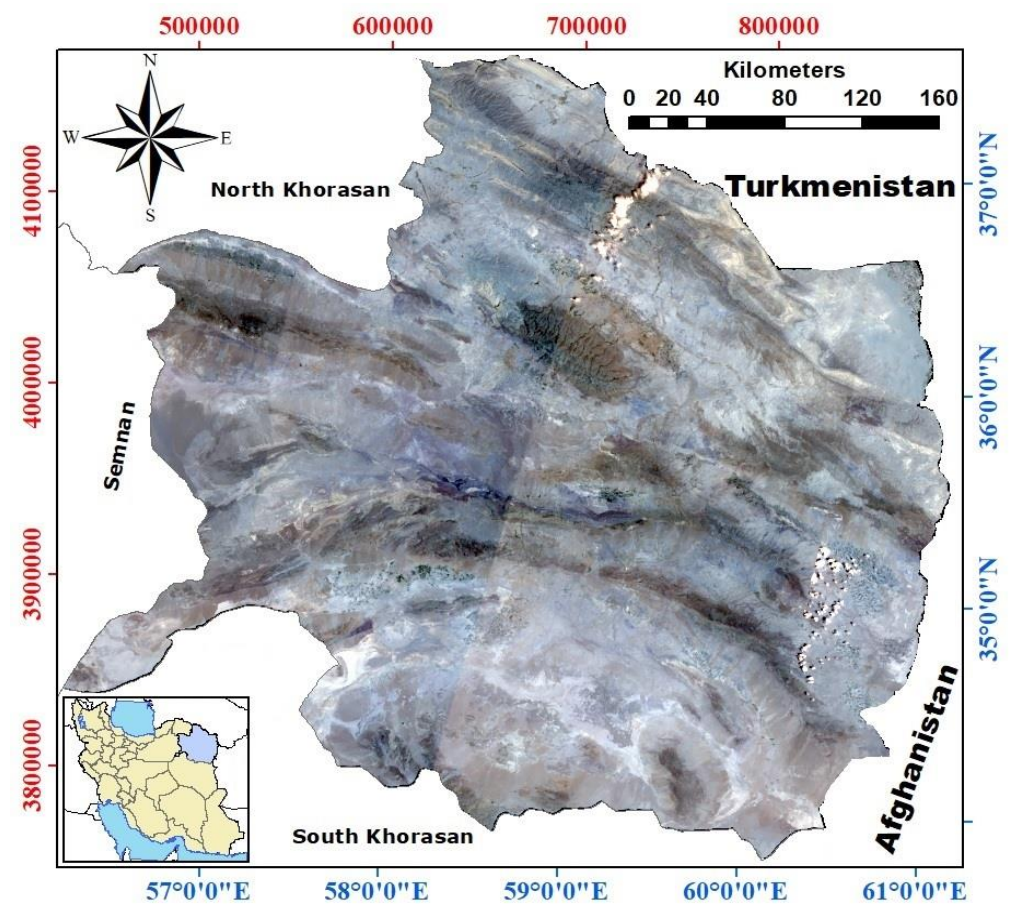

Figure 3. Image of 2001 (the result of combining 12 Landsat 7 images)

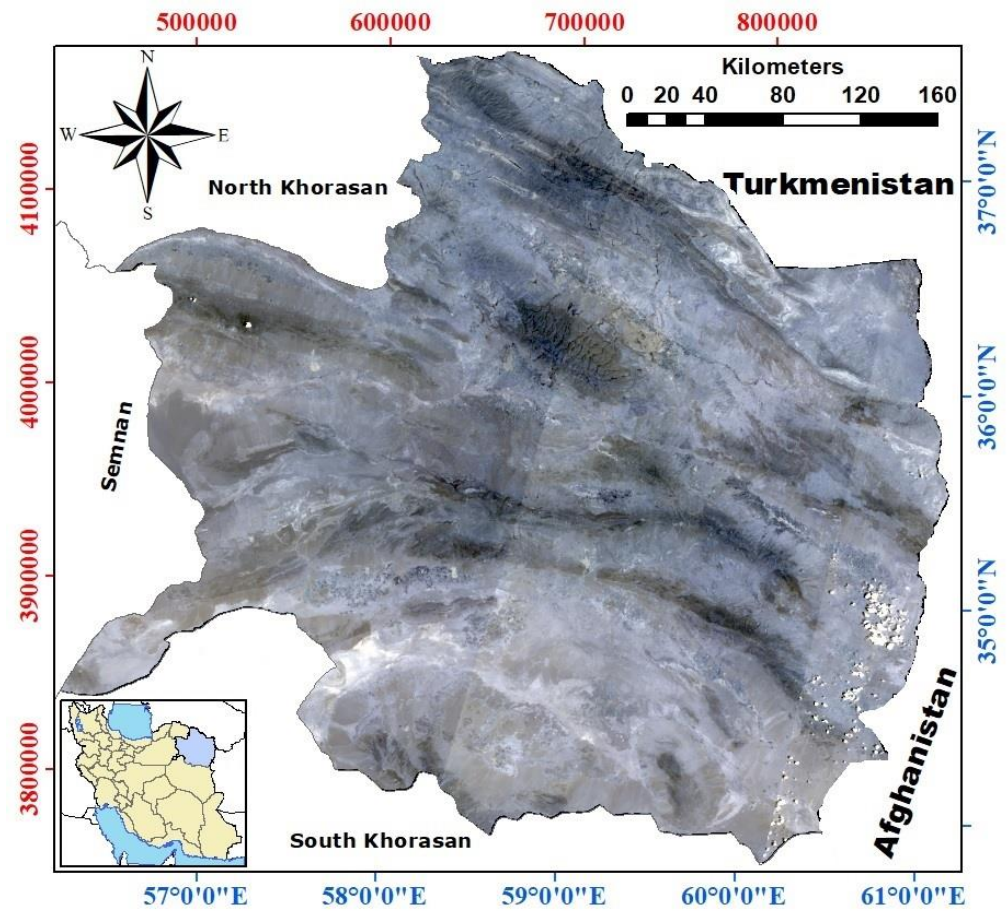

Figure 4. Image of 2015 (the result of combining 12 Landsat 8 images) 


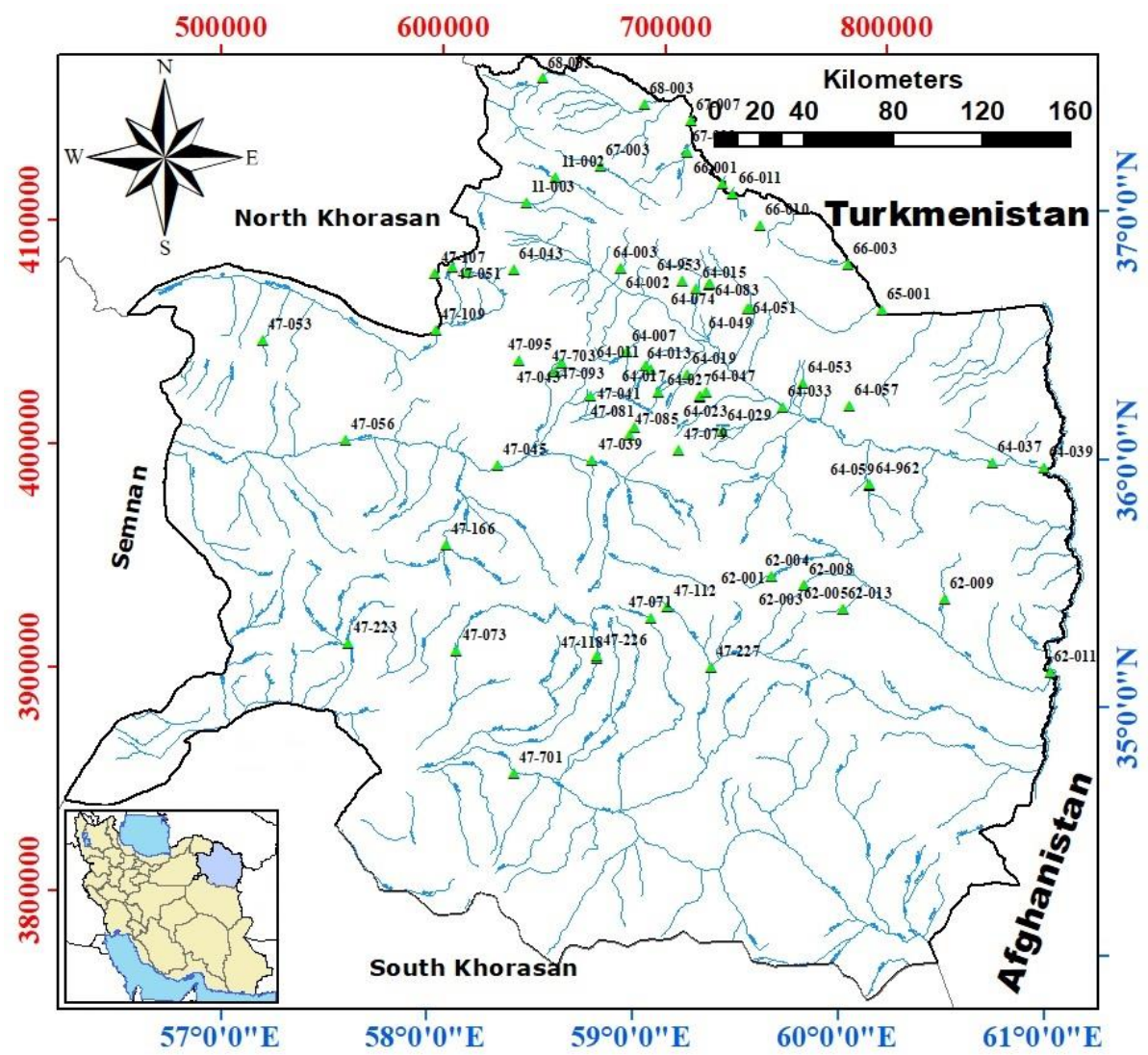

Figure 5. Location of water quality gauge stations and river network in study area

Table 2. Water quality monitoring sites and its characteristics

\begin{tabular}{c|c|c|c|c|c|c|c|c|c}
\hline Row & $\begin{array}{c}\text { Station } \\
\text { code }\end{array}$ & $\begin{array}{c}\text { Area } \\
\left(\mathbf{k m}^{2}\right)\end{array}$ & Latitude & Longitude & Row & $\begin{array}{c}\text { Station } \\
\text { code }\end{array}$ & $\begin{array}{c}\text { Area } \\
\left(\mathbf{k m}^{2}\right)\end{array}$ & Latitude & Longitude \\
\hline 1 & 47041 & 152 & 36.32250 & 58.85694 & 19 & 64017 & 68 & 36.33472 & 59.19667 \\
2 & 47043 & 111 & 36.45806 & 58.71194 & 20 & 64019 & 203 & 36.40028 & 59.33972 \\
3 & 47071 & 76 & 35.42000 & 59.13361 & 21 & 64023 & 116 & 36.30944 & 59.40278 \\
4 & 47073 & 805 & 35.30444 & 58.16694 & 22 & 64027 & 74 & 36.31472 & 59.40111 \\
5 & 47079 & 29 & 36.09639 & 59.28889 & 23 & 64029 & 140 & 36.17167 & 59.51167 \\
6 & 47081 & 53 & 36.19083 & 59.07417 & 24 & 64033 & 9074 & 36.25167 & 59.64528 \\
7 & 47085 & 109 & 36.16083 & 59.04694 & 25 & 64037 & 15964 & 36.00500 & 60.85611 \\
8 & 47093 & 82 & 36.42361 & 58.68083 & 26 & 64039 & 16427 & 35.97528 & 61.10889 \\
9 & 47095 & 491 & 36.47444 & 58.49861 & 27 & 64043 & 41 & 36.84000 & 58.47750 \\
10 & 47166 & 1180 & 35.73306 & 58.12083 & 28 & 64047 & 310 & 36.32750 & 59.43222 \\
11 & 62001 & 273 & 35.57806 & 59.73639 & 29 & 64049 & 432 & 36.65972 & 59.66611 \\
12 & 62003 & 121 & 35.53639 & 59.89556 & 30 & 64059 & 235 & 35.93528 & 60.23806 \\
13 & 62009 & 505 & 35.46278 & 60.59361 & 31 & 65001 & 838 & 36.64111 & 60.33111 \\
14 & 64003 & 240 & 36.83639 & 59.02000 & 32 & 66001 & 228 & 37.16944 & 59.54167 \\
15 & 64007 & 277 & 36.32222 & 59.04083 & 33 & 66003 & 847 & 36.82694 & 60.16806 \\
16 & 64011 & 49 & 36.44333 & 59.13306 & 34 & 67001 & 1239 & 37.30139 & 59.36694 \\
17 & 64013 & 40 & 36.42694 & 59.15750 & 35 & 67003 & 81 & 37.25111 & 58.92500 \\
18 & 64015 & 497 & 36.75139 & 59.38667 & 36 & 68005 & 943 & 37.61500 & 58.64028 \\
\hline
\end{tabular}




\section{Long-term land use change detection}

To find the impact of land use changes on water quality trends, land use changes during the study period investigated (Worrall and Burt, 1999). Using Erdas Imagine 2014 software and RS data, the LULC changes in Razavi Khorasan Province between the years of 1987, 2001 and 2015 were determined in the manner described below.

In the present study, in spite of the positive results of the research experience that used the Maximum likelihood method for categorization (Al-Ahmadi and Hames, 2009), three different supervised classification techniques including Maximum likelihood, Mahalanobis Distance, and Minimum Distance are applied for the classification of Landsat 8 (image of 2015). All non-thermal bands of the images used to generate spectral signatures for classification. For further separating and identifying the phenomena, false-colour images generated (Khoi and Murayama, 2010). These produced images helped to distinguish various types of land use in the study area.

The first step in performing a supervised classification method was to define areas used as training samples for each class. Using random point generation tool in ArcGIS, reference points randomly generated and the accuracy of the classification verified (Jensen, 2015). For this goal, the following steps were employed: first, using a GPS, 200 points were specified for the images of 2015, and after that, the actual ground points compared with the classified maps. Then, by applying GCP (ground control points) and visual interpretation, the overall accuracy assessment of the classified maps of 2015 (three maps that were prepared by the Maximum likelihood, Mahalanobis Distance, and Minimum Distance methods) determined (Schulz et al., 2010). The admitted RMSE between any two dates should not be more than 0.5 pixels (Lunetta and Elvidge, 1998), so the acceptable RMSE between the two images considered less than 0.5 pixels. The results of these three methods were compared and the best method for the classification was chosen.

Following the classification of imagery from the individual years, to specify changes in land use between the intervals (1987-2001 and 2001-2015), Post-Classification Comparison method applied (Erdogan et al., 2015). The post-classification technique supply 'from-to' change information and so, the type of LULC changes that occurred can be easily determined (Yuan et al., 2005). By applying extension X tools in ArcGIS 10.3, the extent of each land use types determined. Also, the transition matrix obtained by cross-tabulating the maps of 1987,2001 , and 2015 . This matrix generally reported in the land use change detection studies (Dewan and Yamaguchi, 2009; Monteiro et al., 2011).

The area of watersheds for each of hydrometric stations delineated by applying ArcGIS software and it used as a foundation map for the analysis. Then the layers of the watershed used to clip 1987, 2001, and 2015 LULC coverage allowing calculation of the effective land uses. For analyzing the spatial distribution of various land use category and land cover transformation, the cross-tabulation method performed. Finally, using cross tabulations in ArcGIS software (Spatial Analyst Tools > Zonal > Tabulate Area), maps of land cover classes compared with each other, as the maps of 1987 and 2001, 2001 and 2015 crossed and aspects of changes extracted.

\section{Long-term trend analysis of water quality}

At hydrometric stations, water quality data are measured daily. In this study, given the fact that water quality data may change over the course of a few days due to short- 
term or local changes, the multi-day average data was used to study the changes in surface water quality. According to Table 1, Landsat 5 images were captured in 1987 between June 16th and June $27^{\text {th }}$ (12 days). Similarly, Landsat 7 images were captured in 2001 between May 29 and July 27 (63 days) and Landsat 8 images in 2015 between June 15 and June $29^{\text {th }}$ (15 days). Therefore, the water quality data of the aforementioned days were averaged and used in subsequent calculations.

For example, in 1987, for the TDS parameter, there are 12 data in each sub-basin (12 days). The average of these 12 data was considered as the value of the TDS parameter in 1987 in each sub-basin. This was done for all 36 sub-basins and the TSD parameter value was obtained in 1987 (36 data for the TDS parameter in 1987). Also in 2001 , for the TDS parameter, there are 63 data in each sub-basin (63 days). The average of these 63 data was considered as the value of the TDS parameter in 2001 in each subbasin. This was done for all 36 sub-basins and the TSD parameter value was obtained in 2001 (36 data for the TDS parameter in 2001). The same way, in 2015, for the TDS parameter, there are 15 data in each sub-basin (15 days). The average of these 15 data was considered as the value of the TDS parameter in 2015 in each sub-basin. This was done for all 36 sub-basins and the TSD parameter value was obtained in 2015 (36 data for the TDS parameter in 2015). The same method was used for other parameters. Considering that 13 parameters were evaluated in this study, 1404 numbers were obtained for modelling.

The Mann-Kendall and Seasonal Kendall tests are the most common trend tests in hydro-meteorological studies for non-normal variables. While, the linear regression and analysis of covariance are some of the parametric methods, which is used for normally distributed variables (Zamani et al., 2013; Sheikhy Narany et al., 2017). We assessed the normality of data by means of the Kolmogorov-Smirnov and Shapiro-Wilk tests and then the appropriate method for trend test was chosen (Pratt and Chang, 2012).

\section{Simulation and predicting of water quality data}

The null hypothesis was water quality is not related to the land use changes at a watershed scale and the statistical analysis employed to test it. A rejected null hypothesis reveals that "there is a relationship between land use changes and water quality". In SPSS software, Spearman's rank correlation analysis applied to finding the relationships between land use types (as an independent variable) and water quality in the 36 hydrometric stations (as a dependent variable) (Tong and Chen, 2002).

For modelling, at first, the amount of land use area in 36 sub-basins extracted using ArcGIS software from the attribute table of each layer. Since some of the land use does not exist in all sub-basin so in modelling, was not used. For example, there is a poor rangeland area in all 36 sub-basins. According to the maps of 1987, 2001, and 2015, 108 land use values (for poor rangeland) are obtained. These data considered as parameter $\mathrm{x}$ and water quality data as a parameter $\mathrm{y}$. But for land use that does not exist in all sub-basin (for example, residential land), the number of data for modelling would be less and may reduce correlation and not be used in modelling.

It is difficult and time-consuming to thoroughly analyze the data of one variable at a time. Because of identifying the relevance of the variables, the multivariate statistics are useful and apply for reducing the number of components in a dataset. Thus, the multivariate linear regression model used to investigate the statistical relationships of land use changes and water quality variables to making model. For this purpose, different types of land use as independent variables (Range, Garden, Residential, etc.) 
and changes in each factor of the surface water quality considered as a dependent variable (TDS, EC, $\mathrm{pH}$, etc). After reducing the number of factors, modelling done with fewer parameters and further simulation of surface water quality performed.

By using relationships between land use types in 1987, 2001, and 2015, the linear regression models created and applied for predicting land use types in the future. The time interval between the selected images for studying land use changes for the years 1987, 2001, and 2015 is 14 years. In order to make a more accurate estimate of land use changes, the time interval for the prediction of variations was chosen 14 years, so that the resulting data would be maximally consistent. Then, by using the regression model that provided for predicting water quality, and the area of land use predicted in 2029, each water quality parameter was simulated.

\section{Results}

Satellite imagery data were analysed with digital image processing methods and spatial analysis techniques to detect spatial-temporal changes in land use. A multitemporal Landsat satellite dataset formed the basis for the change detection procedure. The overall accuracy assessment of the classified maps of 2015 that were prepared by the Maximum likelihood, Mahalanobis Distance, and Minimum Distance methods was 87.3, 83.7, and 78.5, respectively. So, by applying the supervised maximum likelihood classification technique, the images classified (Schulz et al., 2010). Land use maps of Khorasan Razavi Province for the years 1987, 2001 and 2015 showed in Figures 6, 7 and 8, respectively.

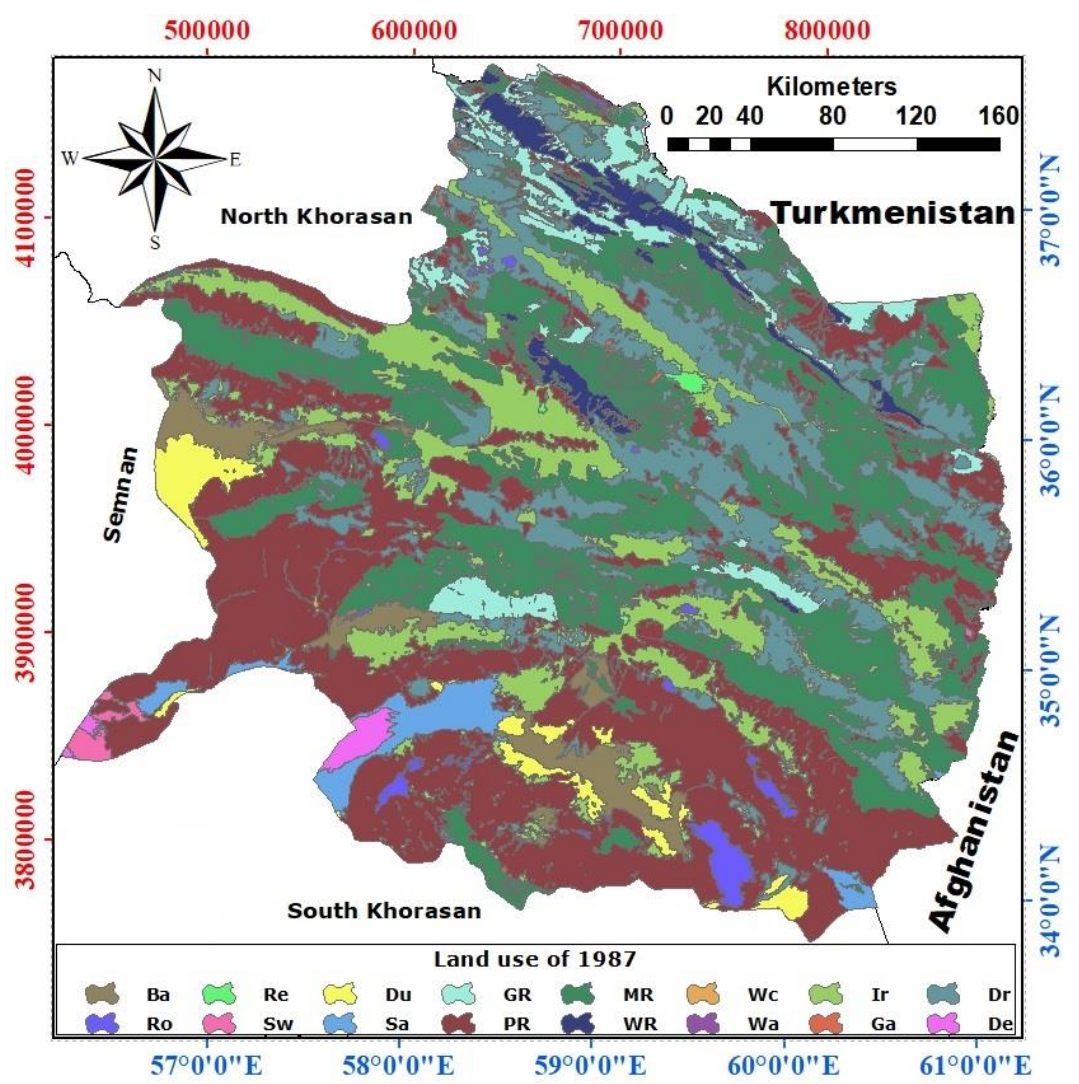

Figure 6. Land use maps of Khorasan Razavi Province for the year 1987 


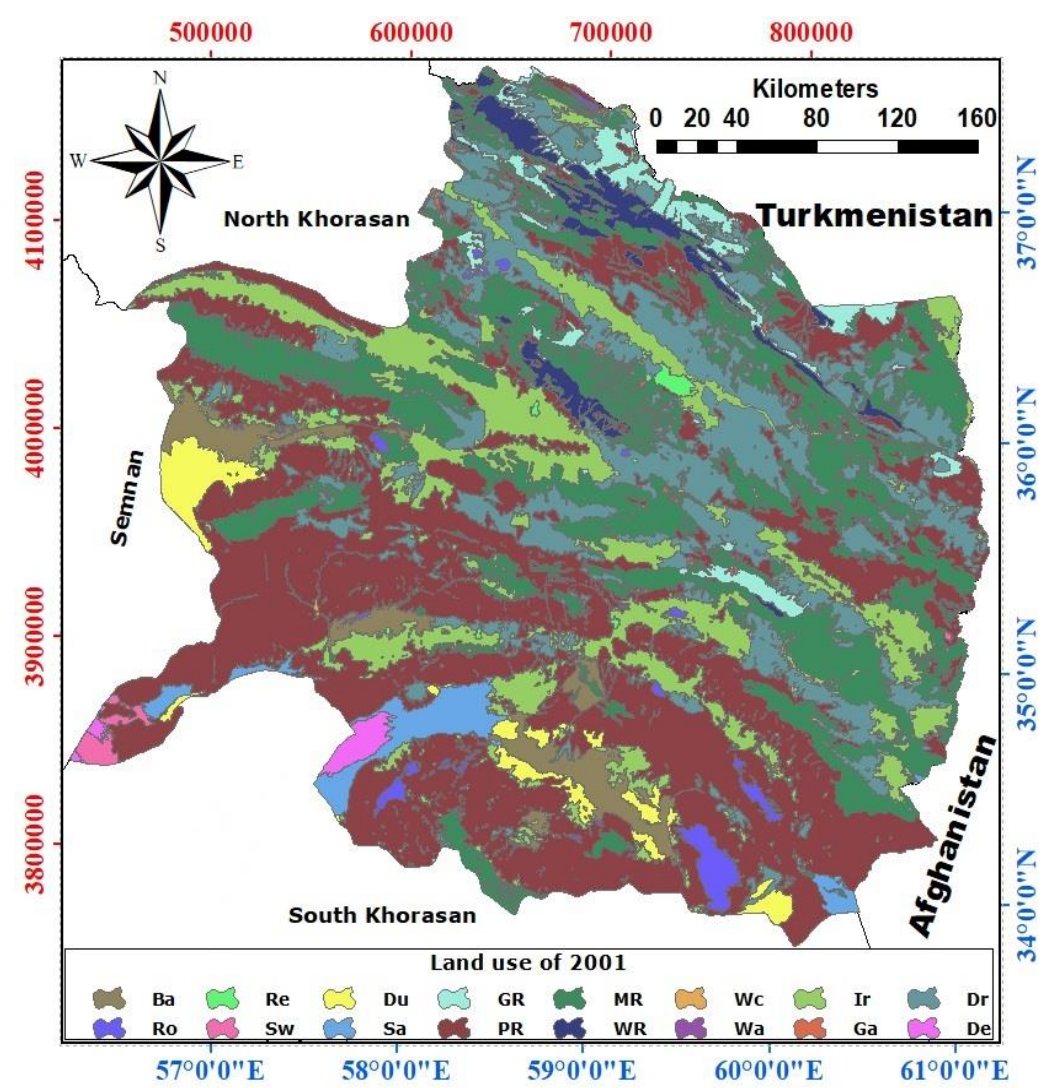

Figure 7. Land use maps of Khorasan Razavi Province for the year 2001

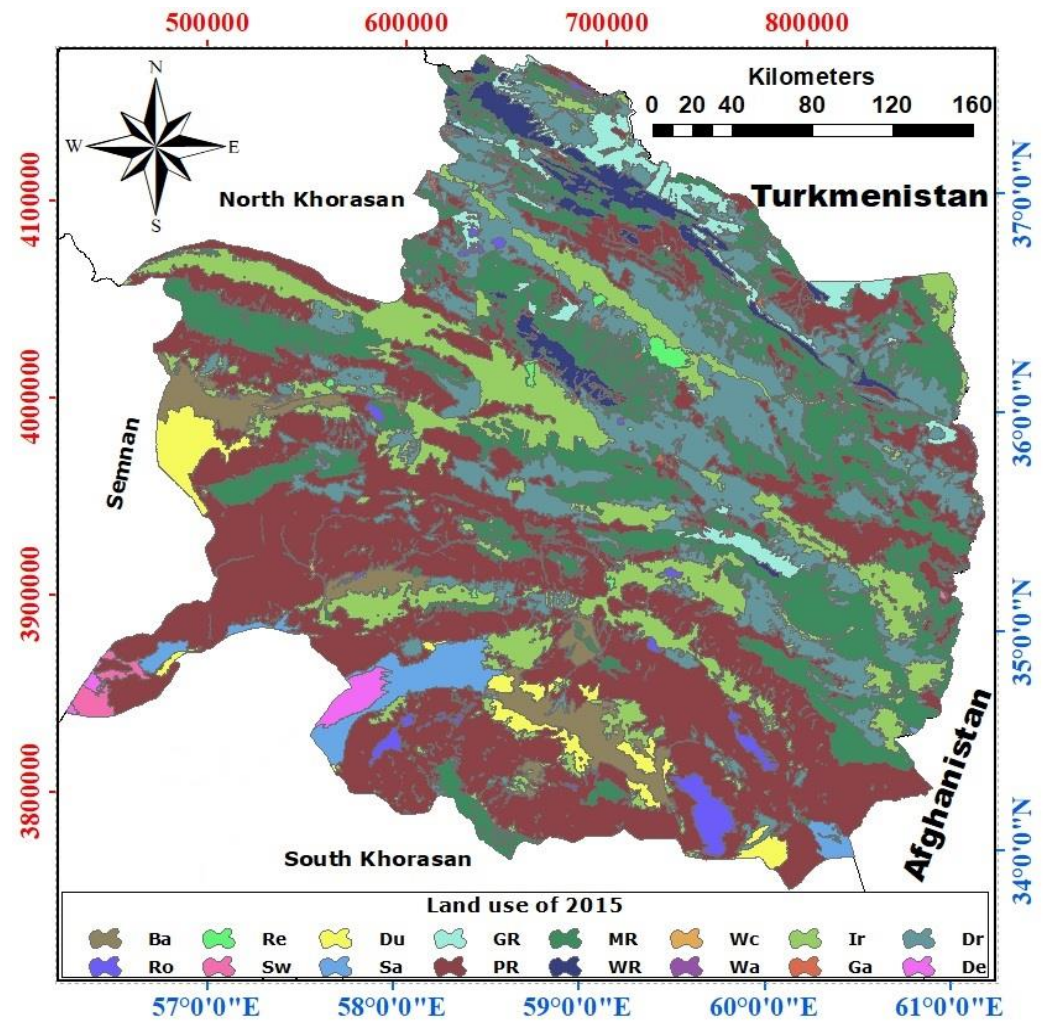

Figure 8. Land use maps of Khorasan Razavi Province for the year 2015 
In the Khorasan Razavi Province identified sixteen land use classes included: Barren (Ba), Rocky (Ro), Residential (Re), Swamp (Sw), Water (Wa), Dunes (Du), Salt marsh (Sa), Irrigated cultivation (Ir), Garden (Ga), Dry farming (Dr), Desert (De), Good rangeland (GR), Medium rangeland (MR), Poor rangeland (PR), Wooded rangeland (WR), Watercourse (Wc). The coverage of each land use class gave as the area $\left(\mathrm{km}^{2}\right)$ and percentage (\%) for the years of 1987, 2001 and 2015 (Table 3).

Table 3. Distribution of land use classes in 1987, 2001 and 2015

\begin{tabular}{c|c|c|c|c|c|c}
\hline \multirow{2}{*}{ Land use } & \multicolumn{2}{|c|}{$\mathbf{1 9 8 7}$} & \multicolumn{2}{c|}{$\mathbf{2 0 0 1}$} & \multicolumn{2}{c}{$\mathbf{2 0 1 5}$} \\
\cline { 2 - 7 } & $\mathbf{( \mathbf { k m } ^ { 2 } )}$ & $\mathbf{( \% )}$ & $\mathbf{( k m}^{\mathbf{}} \mathbf{( \% )}$ & $\mathbf{( \mathbf { \% }} \mathbf{)}$ & $\mathbf{( \% )}$ \\
\hline Barren & 3716.2 & 3.2 & 3638.7 & 3.1 & 3638.7 & 3.1 \\
Rocky & 1325.9 & 1.1 & 1325.9 & 1.1 & 1325.9 & 1.1 \\
Residential & 380.5 & 0.3 & 477.1 & 0.4 & 569.9 & 0.5 \\
Swamp & 403.4 & 0.3 & 402.1 & 0.3 & 400.4 & 0.3 \\
Water & 1.3 & 0.0 & 5.0 & 0.0 & 23.8 & 0.0 \\
Dunes & 2470.6 & 2.1 & 2437.8 & 2.1 & 2318.6 & 2.0 \\
Salt marsh & 2139.9 & 1.8 & 2121.9 & 1.8 & 2121.9 & 1.8 \\
Irrigated cultivation & 14371.7 & 12.2 & 15042.1 & 12.8 & 15135.7 & 12.8 \\
Garden & 946.4 & 0.8 & 947.3 & 0.8 & 947.6 & 0.8 \\
Dry farming & 18229.3 & 15.5 & 18243.5 & 15.5 & 18606.4 & 15.8 \\
Desert & 567.7 & 0.5 & 567.7 & 0.5 & 566.7 & 0.5 \\
Good rangeland & 5296.1 & 4.5 & 3024.4 & 2.6 & 3057.3 & 2.6 \\
Medium rangeland & 27989.7 & 23.7 & 24195.1 & 20.5 & 22783.8 & 19.3 \\
Poor rangeland & 36879.4 & 31.3 & 42330.6 & 35.9 & 43295.5 & 36.7 \\
Wooded rangeland & 3093.3 & 2.6 & 3052.2 & 2.6 & 3019.3 & 2.6 \\
Watercourse & 154.4 & 0.1 & 154.4 & 0.1 & 154.4 & 0.1 \\
\hline Total & 117966.0 & 100 & 117966.0 & 100 & 117966.0 & 100 \\
\hline
\end{tabular}

In Khorasan Razavi Province, between 1987 and 2001, the highest incremental changes in the percentage of land use area were 378, 125 and 115 related to water area, residential and poor range, respectively. The maximum of incremental changes in the area was $5449 \mathrm{~km}^{2}$ (poor range), $670 \mathrm{~km}^{2}$ (irrigated cultivation) and $96 \mathrm{~km}^{2}$ (residential). Also, the maximum decreasing changes in the area were $3794 \mathrm{~km}^{2}$, $2271 \mathrm{~km}^{2}$, and $77 \mathrm{~km}^{2}$ related to medium range, good range, and barren, respectively. In this area, during 2001-2015, the highest incremental changes in the percentage of land use area were 473, 119 and 102 percent related to water area, residential and dry farming, respectively. The maximum of incremental changes in the area were $961 \mathrm{~km}^{2}$ (poor range), $362 \mathrm{~km}^{2}$ (dry farming) and $92 \mathrm{~km}^{2}$ (residential). Also, the highest decreasing changes related to medium range $\left(1411 \mathrm{~km}^{2}\right)$, dunes $\left(119 \mathrm{~km}^{2}\right)$ and wooded rangeland $\left(32 \mathrm{~km}^{2}\right)$, respectively.

In ArcGIS software, using land use maps of Razavi Khorasan province (1987, 2001 and 2015) and the surface of 36 catchments, land use changes in the watershed of hydrometric stations extracted. Thus, a total of 108 land use maps were prepared. Using linear regression models (Table 4), land use changes in the years 2029 estimated (Table 5). 
Table 4. Equations for predicting land use area. " $y$ " is area $\left(\mathrm{km}^{2}\right)$ and " $x$ " is time (year)

\begin{tabular}{c|c|c|c}
\hline Row & Land use & $\mathbf{R}^{\mathbf{2}}$ & Equation \\
\hline 1 & Barren & 0.7500 & $\mathrm{y}=-2.7659 \mathrm{x}+9,199.1016$ \\
2 & Rocky & 1.0000 & $\mathrm{y}=1,325.9000$ \\
3 & Residential & 0.9999 & $\mathrm{y}=6.7630 \mathrm{x}-13,057.0028$ \\
4 & Swamp & 0.9941 & $\mathrm{y}=-0.1071 \mathrm{x}+616.3520$ \\
5 & Water & 0.8697 & $\mathrm{y}=0.8038 \mathrm{x}-1,598.4082$ \\
6 & Dunes & 0.9027 & $\mathrm{y}=-5.4279 \mathrm{x}+13,270.1455$ \\
7 & Salt marsh & 0.7500 & $\mathrm{y}=-0.6411 \mathrm{x}+3,410.7148$ \\
8 & Irrigated cultivation & 0.8403 & $\mathrm{y}=27.2867 \mathrm{x}-39,750.8704$ \\
9 & Garden & 0.9164 & $\mathrm{y}=0.0408 \mathrm{x}+865.4379$ \\
10 & Dry farming & 0.7781 & $\mathrm{y}=13.4683 \mathrm{x}-8,590.3179$ \\
11 & Desert & 0.7500 & $\mathrm{y}=-0.0357 \mathrm{x}+638.6401$ \\
12 & Good rangeland & 0.7390 & $\mathrm{y}=-79.9566 \mathrm{x}+163,785.8109$ \\
13 & Medium rangeland & 0.9347 & $\mathrm{y}=-185.9272 \mathrm{x}+397,029.9174$ \\
14 & Poor rangeland & 0.8599 & $\mathrm{y}=229.1433 \mathrm{x}-417,680.5879$ \\
15 & Wooded rangeland & 0.9959 & $\mathrm{y}=-2.6445 \mathrm{x}+8,346.4889$ \\
16 & Watercourse & 1.0000 & $\mathrm{y}=154.4400$ \\
\hline
\end{tabular}

Table 5. Estimate of land use changes in study area, 2015-2029 $\left(\mathrm{km}^{2}\right)$

\begin{tabular}{c|c|c|c|c|c|c|c|c|c|c|c|c|c|c|c|c|c}
\hline Land use & Ba & Ro & $\mathbf{R e}$ & $\mathbf{S w}$ & $\mathbf{W a}$ & $\mathbf{D u}$ & $\mathbf{S a}$ & $\mathbf{I r}$ & $\mathbf{G a}$ & $\mathbf{D r}$ & $\mathbf{D e}$ & $\mathbf{G R}$ & $\mathbf{M R}$ & $\mathbf{P R}$ & $\mathbf{W R}$ & $\mathbf{W c}$ & $\begin{array}{c}\text { Total } \\
(\mathbf{2 0 1 5})\end{array}$ \\
\hline Ba & 3553 & 0 & 2 & 0 & 0 & 0 & 0 & 83 & 0 & 1 & 0 & 0 & 0 & 0 & 0 & 0 & 3639 \\
$\mathbf{R o}$ & 0 & 1326 & 0 & 0 & 0 & 0 & 0 & 0 & 0 & 0 & 0 & 0 & 0 & 0 & 0 & 0 & 1326 \\
$\mathbf{R e}$ & 0 & 0 & 570 & 0 & 0 & 0 & 0 & 0 & 0 & 0 & 0 & 0 & 0 & 0 & 0 & 0 & 570 \\
Dr & 0 & 0 & 51 & 0 & 1 & 0 & 0 & 151 & 3 & 18400 & 0 & 0 & 0 & 0 & 0 & 0 & 18606 \\
Sw & 0 & 0 & 0 & 403 & 0 & 0 & 0 & 0 & 0 & 0 & 0 & 0 & 0 & 0 & 0 & 0 & 403 \\
Wa & 0 & 0 & 0 & 0 & 24 & 0 & 0 & 0 & 0 & 0 & 0 & 0 & 0 & 0 & 0 & 0 & 24 \\
Ga & 0 & 0 & 8 & 0 & 1 & 0 & 0 & 0 & 944 & 0 & 0 & 0 & 0 & 0 & 0 & 0 & 953 \\
Du & 0 & 0 & 0 & 0 & 0 & 2284 & 0 & 18 & 0 & 0 & 0 & 0 & 17 & 0 & 0 & 0 & 2319 \\
Sa & 0 & 0 & 0 & 0 & 0 & 0 & 2104 & 6 & 1 & 0 & 0 & 0 & 0 & 10 & 0 & 0 & 2122 \\
Ir & 10 & 0 & 23 & 0 & 0 & 0 & 0 & 15089 & 6 & 0 & 0 & 0 & 0 & 0 & 0 & 2 & 15130 \\
PR & 0 & 0 & 11 & 0 & 2 & 0 & 0 & 373 & 0 & 70 & 0 & 0 & 42828 & 2 & 0 & 6 & 43291 \\
De & 0 & 0 & 0 & 0 & 0 & 0 & 0 & 0 & 0 & 0 & 568 & 0 & 0 & 0 & 0 & 0 & 568 \\
GR & 0 & 0 & 0 & 0 & 0 & 0 & 0 & 0 & 0 & 0 & 0 & 1746 & 472 & 839 & 0 & 0 & 3057 \\
MR & 0 & 0 & 4 & 0 & 0 & 0 & 0 & 107 & 0 & 127 & 0 & 0 & 4077 & 18468 & 0 & 0 & 22784 \\
WR & 0 & 0 & 0 & 0 & 0 & 0 & 0 & 0 & 0 & 0 & 0 & 0 & 0 & 40 & 2979 & 0 & 3019 \\
Wc & 0 & 0 & 0 & 0 & 0 & 0 & 0 & 2 & 0 & 0 & 0 & 0 & 0 & 0 & 0 & 152 & 154 \\
\hline Total & 3564 & 1326 & 669 & 403 & 28 & 2284 & 2104 & 15830 & 954 & 18598 & 568 & 1746 & 47394 & 19360 & 2979 & 160 & 117966 \\
$(\mathbf{2 0 2 9})$ &
\end{tabular}

Ba: Barren, Ro: Rocky, Re: Residential, Sw: Swamp, Wa: Water, Du: Dunes, Sa: Salt marsh, Ir: Irrigated cultivation, Ga: Garden, Dr: Dry farming, De: Desert, GR: Good rangeland, MR: Medium rangeland, PR: Poor rangeland, WR: Wooded rangeland, Wc: Watercourse

Because of identifying the relevance of the variables, the multivariate statistics are useful and so apply for reducing the number of components in a dataset. Based on the 
findings, among the 16 types of land use, eight items showed the highest correlation. The eight items were Residential, Irrigated cultivation, Garden, Dry farming, Good rangeland, Medium rangeland, Poor rangeland, and Wooded rangeland.

Using Pearson correlation analysis, the correlation coefficient of these eight land use parameters versus water quality parameters were investigated. Results showed in Table 6.

Table 6. Results of Pearson correlation analysis for change in LULC area to change of water quality variables

\begin{tabular}{|c|c|c|c|c|c|c|c|c|c|}
\hline $\begin{array}{l}\text { Physico- } \\
\text { chemicals }\end{array}$ & Parameters & $\operatorname{Re}$ & $\mathbf{I r}$ & Ga & Dr & GR & MR & PR & WR \\
\hline \multirow{3}{*}{$\mathrm{Ca}$} & Pearson correlation & $.866^{* *}$ & .504 & $.626^{* * *}$ & $.593^{* *}$ & $.689^{* * *}$ & $.566^{* *}$ & $.549^{* *}$ & $.430^{*}$ \\
\hline & Sig. (2-tailed) & .005 & .114 & .000 & .001 & .002 & .000 & .005 & .025 \\
\hline & $\mathrm{N}$ & 8 & 11 & 33 & 26 & 17 & 36 & 24 & 27 \\
\hline \multirow{3}{*}{$\mathrm{Mg}$} & Pearson correlation & $.902^{* *}$ & .242 & $.453^{* *}$ & .309 & $.508^{*}$ & $.356^{*}$ & .383 & $.423^{*}$ \\
\hline & Sig. (2-tailed) & .002 & .474 & .008 & .125 & .038 & .033 & .065 & .028 \\
\hline & $\mathrm{N}$ & 8 & 11 & 33 & 26 & 17 & 36 & 24 & 27 \\
\hline \multirow{3}{*}{$\mathrm{Na}$} & Pearson correlation & $.853^{* * *}$ & .052 & $.642^{* *}$ & .219 & $.734^{* * *}$ & .239 & .393 & .294 \\
\hline & Sig. (2-tailed) & .007 & .880 & .000 & .282 & .001 & .160 & .057 & .137 \\
\hline & $\mathrm{N}$ & 8 & 11 & 33 & 26 & 17 & 36 & 24 & 27 \\
\hline \multirow{3}{*}{ K } & Pearson correlation & $.761^{*}$ & .476 & $.862^{* *}$ & $.600^{* *}$ & $.629^{* * *}$ & $.604^{* *}$ & $.696^{* *}$ & .367 \\
\hline & Sig. (2-tailed) & .028 & .139 & .000 & .001 & .007 & .000 & .000 & .060 \\
\hline & $\mathrm{N}$ & 8 & 11 & 33 & 26 & 17 & 36 & 24 & 27 \\
\hline \multirow{3}{*}{$\mathrm{Cl}$} & Pearson correlation & $.872^{* * *}$ & .042 & $.662^{* *}$ & .202 & $.736^{* *}$ & .215 & .373 & .272 \\
\hline & Sig. (2-tailed) & .005 & .903 & .000 & .321 & .001 & .208 & .073 & .170 \\
\hline & $\mathrm{N}$ & 8 & 11 & 33 & 26 & 17 & 36 & 24 & 27 \\
\hline \multirow{3}{*}{$\mathrm{CO}_{3}$} & Pearson correlation & -.291 & -.284 & -.109 & -.144 & -.164 & -.099 & -.161 & .019 \\
\hline & Sig. (2-tailed) & .484 & .397 & .545 & .484 & .529 & .566 & .451 & .925 \\
\hline & $\mathrm{N}$ & 8 & 11 & 33 & 26 & 17 & 36 & 24 & 27 \\
\hline \multirow{3}{*}{$\mathrm{HCO}_{3}$} & Pearson correlation & $.954^{* * *}$ & $.832^{* *}$ & $.747^{* * *}$ & $.665^{* *}$ & $.582^{*}$ & $.657^{* *}$ & $.720^{* *}$ & $.402^{*}$ \\
\hline & Sig. (2-tailed) & .000 & .001 & .000 & .000 & .014 & .000 & .000 & .037 \\
\hline & $\mathrm{N}$ & 8 & 11 & 33 & 26 & 17 & 36 & 24 & 27 \\
\hline \multirow{3}{*}{$\mathrm{SO} 4$} & Pearson correlation & $.857^{* * *}$ & .246 & $.539^{* *}$ & .387 & $.611^{* *}$ & $.420^{*}$ & $.446^{*}$ & $.432 *$ \\
\hline & Sig. (2-tailed) & .007 & .467 & .001 & .051 & .009 & .011 & .029 & .024 \\
\hline & $\mathrm{N}$ & 8 & 11 & 33 & 26 & 17 & 36 & 24 & 27 \\
\hline \multirow{3}{*}{ EC } & Pearson correlation & $.888^{* * *}$ & .182 & $.679^{* * *}$ & .357 & $.740^{* *}$ & $.379^{*}$ & $.493^{*}$ & $.409^{*}$ \\
\hline & Sig. (2-tailed) & .003 & .592 & .000 & .073 & .001 & .023 & .014 & .034 \\
\hline & $\mathrm{N}$ & 8 & 11 & 33 & 26 & 17 & 36 & 24 & 27 \\
\hline \multirow{3}{*}{$\mathrm{pH}$} & Pearson correlation & $-.969^{* * *}$ & $-.909^{* *}$ & $-.839^{* *}$ & $-.804^{* *}$ & $-.765^{* *}$ & $-.783^{* *}$ & $-.845^{* *}$ & $-.420^{*}$ \\
\hline & Sig. (2-tailed) & .000 & .000 & .000 & .000 & .000 & .000 & .000 & .029 \\
\hline & $\mathrm{N}$ & 8 & 11 & 33 & 26 & 17 & 36 & 24 & 27 \\
\hline \multirow{3}{*}{ TDS } & Pearson correlation & $.888^{* * *}$ & .182 & $.679^{* *}$ & .357 & $.740^{* *}$ & $.379^{*}$ & $.493^{*}$ & $.409^{*}$ \\
\hline & Sig. (2-tailed) & .003 & .592 & .000 & .073 & .001 & .023 & .014 & .034 \\
\hline & $\mathrm{N}$ & 8 & 11 & 33 & 26 & 17 & 36 & 24 & 27 \\
\hline \multirow{3}{*}{ SAR } & Pearson correlation & .641 & .018 & $.500^{* * *}$ & .180 & $.704^{* * *}$ & .205 & .367 & .276 \\
\hline & Sig. (2-tailed) & .087 & .958 & .003 & .378 & .002 & .231 & .078 & .164 \\
\hline & $\mathrm{N}$ & 8 & 11 & 33 & 26 & 17 & 36 & 24 & 27 \\
\hline \multirow{3}{*}{ Thard } & Pearson correlation & $.898^{* * *}$ & .446 & $.595^{* * *}$ & $.506^{* *}$ & $.653^{* *}$ & $.513^{* *}$ & $.520^{* *}$ & $.447^{*}$ \\
\hline & Sig. (2-tailed) & .002 & .169 & .000 & .008 & .004 & .001 & .009 & .019 \\
\hline & $\mathrm{N}$ & 8 & 11 & 33 & 26 & 17 & 36 & 24 & 27 \\
\hline
\end{tabular}

Re: Residential, Ir: Irrigated cultivation, Ga: Garden, Dr: Dry farming, GR: Good rangeland, MR: Medium rangeland, PR: Poor rangeland, WR: Wooded rangeland 
Using the data in Table 6 and the linear regression model, each water quality parameter was modelled (Table 7). The general formula was the linear equation including " $y=\left(\right.$ variable $\left.^{*} \mathrm{x}\right)+$ constant". The ' $\mathrm{x}$ ' parameter value selected based on the highest correlation, in Table 6. For example, for predicting the parameter magnesium $(\mathrm{Mg})$ the highest correlation belongs to residential land use $\left(\mathrm{R}^{2}=0.902\right)$, so the area of the residential land use used as ' $x$ '. No models were available to predict the amount of potassium. Then, using the linear regression model was trying to estimate water quality variables in the years 2029 (Table 8). Results demonstrated that except calcium (Ca), Carbonate $\left(\mathrm{CO}_{3}\right)$ and Bicarbonate $\left(\mathrm{HCO}_{3}\right)$, the models estimate all other water quality variables with an acceptable degree of accuracy (P-value $<0.05)$.

\section{Discussion and conclusions}

One of the objectives of this study was to investigate the significance of land use change. The results showed that changes in the direction of a significant decline in good rangeland and a significant increase in poor rangeland that is in agreement with the findings by (Farazmand et al., 2018).

In the present study, three different supervised classification techniques including Maximum likelihood, Mahalanobis Distance, and Minimum Distance are applied for the classification. Results showed that the Maximum likelihood method gave the best results and that is in agreement with results found in other environments by Al-Ahmadi and Hames (2009) and Schulz et al. (2010).

The basic goal of this study was to linking LULC changes to surface water quality variation by using GIS and RS technique. Current methods of estimating water quality in river basins based on land-use patterns are still developing. In this study, we used 36 basins as a case study to consider the relationships between land use and water quality. The relation between water quality and land use types could be different at the various scales of rivers. However, through the analysis of the correlation between water quality variables and various land use types, different land cover patterns that could affect water quality can be recognized.

Table 7. Linear regression models for physic-chemicals and LULC

\begin{tabular}{c|c|c|c|c|c}
\hline \multirow{2}{*}{ Water quality variables } & \multicolumn{5}{|c}{ Model summary } \\
\cline { 2 - 6 } & Constant & Variable & $\mathbf{t}$ & $\mathbf{R}$ & Sig. \\
\hline $\mathrm{Ca}$ & 2.487 & $4.521 \mathrm{E}-5$ & 1.569 & 0.299 & 0.129 \\
$\mathrm{Mg}$ & 2.235 & 0.000 & 2.296 & 0.501 & 0.036 \\
$\mathrm{Na}$ & 2.402 & 0.000 & 2.815 & 0.567 & 0.012 \\
$\mathrm{~K}$ & - & - & - & - & - \\
$\mathrm{Cl}$ & 1.353 & 0.000 & 2.143 & 0.472 & 0.048 \\
$\mathrm{CO}_{3}$ & 0.006 & $-2.59 \mathrm{E}-7$ & -0.782 & 0.155 & 0.442 \\
$\mathrm{HCO}$ & 3.557 & $4.823 \mathrm{E}-7$ & 0.733 & 0.131 & 0.469 \\
$\mathrm{SO} 4$ & 1.973 & 0.000 & 3.753 & 0.559 & 0.001 \\
$\mathrm{EC}$ & 691.375 & 0.058 & 2.770 & 0.570 & 0.014 \\
$\mathrm{pH}$ & 8.028 & $-4.22 \mathrm{E}-7$ & -2.663 & 0.664 & 0.026 \\
$\mathrm{TDS}$ & 308.124 & 0.041 & 2.558 & 0.772 & 0.043 \\
$\mathrm{SAR}$ & 0.499 & 0.000 & 2.897 & 0.587 & 0.010 \\
\hline Total hardness & 29.671 & 0.003 & 2.535 & 0.542 & 0.018 \\
\hline
\end{tabular}

$\mathrm{y}=\left(\operatorname{variable}^{*} \mathrm{x}\right)+\mathrm{constant}$ 
Table 8. Estimated surface water quality variables in the year 2029

\begin{tabular}{|c|c|c|c|c|c|c|c|c|c|c|c|c|c|c|}
\hline Row & $\begin{array}{c}\text { Station } \\
\text { code }\end{array}$ & $\mathrm{Ca}$ & Mg & $\mathbf{N a}$ & $\mathbf{K}$ & Cl & $\mathrm{CO}_{3}$ & $\mathrm{HCO}_{3}$ & SO4 & EC & pH & TDS & SAR & Total hardness \\
\hline 1 & 47041 & - & 2.2 & 2.4 & - & 1.4 & - & - & 2.0 & 697.7 & 8.0 & 312.6 & 1.5 & 225.1 \\
\hline 2 & 47043 & - & 2.3 & 2.5 & - & 1.4 & - & - & 2.1 & 746.7 & 8.0 & 347.3 & 1.5 & 232.7 \\
\hline 3 & 47071 & - & 2.3 & 2.5 & - & 1.4 & - & - & 2.0 & 724.2 & 8.0 & 331.4 & 1.5 & 229.2 \\
\hline 4 & 47073 & - & 2.5 & 2.7 & - & 1.6 & - & - & 2.2 & 850.6 & 8.0 & 420.7 & 1.7 & 248.8 \\
\hline 5 & 47079 & - & 2.3 & 2.4 & - & 1.4 & - & - & 2.0 & 709.7 & 8.0 & 321.1 & 1.5 & 227.0 \\
\hline 6 & 47081 & - & 2.3 & 2.4 & - & 1.4 & - & - & 2.0 & 709.0 & 8.0 & 320.6 & 1.5 & 226.9 \\
\hline 7 & 47085 & - & 2.3 & 2.5 & - & 1.4 & - & - & 2.1 & 740.7 & 8.0 & 343.0 & 1.5 & 231.8 \\
\hline 8 & 47093 & - & 2.3 & 2.5 & - & 1.4 & - & - & 2.0 & 719.3 & 8.0 & 327.8 & 1.5 & 228.5 \\
\hline 9 & 47095 & - & 2.4 & 2.5 & - & 1.5 & - & - & 2.1 & 770.4 & 8.0 & 364.0 & 1.6 & 236.4 \\
\hline 10 & 47166 & - & 2.2 & 2.4 & - & 1.4 & - & - & 2.0 & 691.4 & 8.0 & 308.1 & 1.5 & 224.1 \\
\hline 11 & 62001 & - & 2.5 & 2.6 & - & 1.6 & - & - & 2.2 & 834.4 & 8.0 & 409.2 & 1.7 & 246.3 \\
\hline 12 & 62003 & - & 2.4 & 2.6 & - & 1.5 & - & - & 2.1 & 788.6 & 8.0 & 376.8 & 1.6 & 239.2 \\
\hline 13 & 62009 & - & 2.2 & 2.4 & - & 1.4 & - & - & 2.0 & 691.4 & 8.0 & 308.1 & 1.5 & 224.1 \\
\hline 14 & 64003 & - & 2.3 & 2.5 & - & 1.4 & - & - & 2.0 & 735.6 & 8.0 & 339.4 & 1.5 & 231.0 \\
\hline 15 & 64007 & - & 2.4 & 2.6 & - & 1.5 & - & - & 2.1 & 793.6 & 8.0 & 380.4 & 1.6 & 240.0 \\
\hline 16 & 64011 & - & 2.2 & 2.4 & - & 1.4 & - & - & 2.0 & 697.8 & 8.0 & 312.7 & 1.5 & 225.1 \\
\hline 17 & 64013 & - & 2.3 & 2.4 & - & 1.4 & - & - & 2.0 & 704.7 & 8.0 & 317.6 & 1.5 & 226.2 \\
\hline 18 & 64015 & - & 2.4 & 2.6 & - & 1.6 & - & - & 2.2 & 810.6 & 8.0 & 392.4 & 1.7 & 242.6 \\
\hline 19 & 64017 & - & 2.3 & 2.5 & - & 1.4 & - & - & 2.1 & 736.4 & 8.0 & 340.0 & 1.5 & 231.1 \\
\hline 20 & 64019 & - & 2.5 & 2.7 & - & 1.7 & - & - & 2.3 & 866.0 & 8.0 & 431.6 & 1.8 & 251.2 \\
\hline 21 & 64023 & - & 2.3 & 2.5 & - & 1.5 & - & - & 2.1 & 751.8 & 8.0 & 350.9 & 1.6 & 233.5 \\
\hline 22 & 64027 & - & 2.4 & 2.5 & - & 1.5 & - & - & 2.1 & 761.5 & 8.0 & 357.7 & 1.6 & 235.0 \\
\hline 23 & 64029 & - & 2.4 & 2.5 & - & 1.5 & - & - & 2.1 & 774.4 & 8.0 & 366.8 & 1.6 & 237.0 \\
\hline 24 & 64033 & - & 4.8 & 5.0 & - & 3.9 & - & - & 4.6 & 2194.4 & 7.8 & 1370.6 & 4.0 & 457.4 \\
\hline 25 & 64037 & - & 5.9 & 6.0 & - & 5.0 & - & - & 5.6 & 2803.3 & 7.7 & 1801.1 & 5.1 & 551.9 \\
\hline 26 & 64039 & - & 5.9 & 6.0 & - & 5.0 & - & - & 5.6 & 2803.3 & 7.6 & 1801.1 & 5.1 & 551.9 \\
\hline 27 & 64043 & - & 2.2 & 2.4 & - & 1.4 & - & - & 2.0 & 691.4 & 8.0 & 308.1 & 1.5 & 224.1 \\
\hline 28 & 64047 & - & 2.6 & 2.8 & - & 1.7 & - & - & 2.3 & 906.7 & 8.0 & 460.4 & 1.8 & 257.6 \\
\hline 29 & 64049 & - & 2.4 & 2.6 & - & 1.5 & - & - & 2.1 & 781.0 & 8.0 & 371.5 & 1.6 & 238.0 \\
\hline 30 & 64059 & - & 2.4 & 2.5 & - & 1.5 & - & - & 2.1 & 760.0 & 8.0 & 356.6 & 1.6 & 234.8 \\
\hline 31 & 65001 & - & 2.9 & 3.0 & - & 2.0 & - & - & 2.6 & 1063.3 & 8.0 & 571.1 & 2.1 & 281.9 \\
\hline 32 & 66001 & - & 2.3 & 2.5 & - & 1.5 & - & - & 2.1 & 756.9 & 8.0 & 354.4 & 1.6 & 234.3 \\
\hline 33 & 66003 & - & 2.6 & 2.7 & - & 1.7 & - & - & 2.3 & 875.1 & 8.0 & 438.0 & 1.8 & 252.7 \\
\hline 34 & 67001 & - & 2.5 & 2.7 & - & 1.6 & - & - & 2.3 & 856.1 & 8.0 & 424.5 & 1.7 & 249.7 \\
\hline 35 & 67003 & - & 2.4 & 2.6 & - & 1.6 & - & - & 2.2 & 812.9 & 8.0 & 394.0 & 1.7 & 243.0 \\
\hline 36 & 68005 & - & 2.3 & 2.5 & - & 1.5 & - & - & 2.1 & 753.5 & 8.0 & 352.0 & 1.6 & 233.8 \\
\hline
\end{tabular}

Our results proposed that Garden, Irrigated cultivation and Residential land uses can be a parameter affecting the water quality in the study area. Also, results represented that an overview of the relationship between land use and water quality could provide a combination of large-scale investigations and multivariate statistical techniques. The research showed that the concentration of Electricity Conductivity (EC), Sodium Adsorption Ratio (SAR) and Total Hardness (TH) varied in various sub-basins. Results 
demonstrated that in 8 out of 13 models can estimate water quality variables with a correlation coefficient of $60 \%$, approximately.

The relevance of land use changes and water quality parameters is complex and sitespecific, while the correlation coefficients vary among sub-basin. These results add to the body of research studies accomplished by (Du Plessis et al., 2014) in South Africa, (Wan et al., 2014) in China, (Kibena et al., 2014) in Zimbabwe and (Maimaitijiang et al., 2015) in the USA.

The findings of this research assist policymakers and watershed managers in developing catchment management plans to effectively protect water quality conditions. Therefore, figuring out the effects of changes in LULC is serious for retaining a favourite level of water quality and for restoring water quality in affected areas. However, consequence researches in similar environments can inform that changes in land use and land management practices are initial factors responsible for the variation of receiving water quality. One of the most regular approaches to test these relationships is to develop statistical correlations between water chemistry and current land use in the drainage basins of surface-water sampling points (Wayland et al., 2002). Considering the limitations of this study, the results are only valid in the study area. However, the results and methodology in this study still have implications for water quality management and land use planning in the future for the study area.

\section{Recommendations}

The results of this study propose that land use change is one of the main parameters causing water quality changes. It is suggested for making model use additional layers of parameters such as geomorphology, geology, soil, etc. to increase the accuracy and the coefficient of determination. Further study with a better design of spatial and temporal sampling regime may better clarify the complex nature of the relationship between land use and water quality. Future research for linking the finding of hydrological processes with different pollutant transfer processes is needed. Also, to obtain superior data on the linkages between land use patterns and water quality parameters, a water sampling point per sub-basin is required, as well as an increase in monitoring sites, so that information on smaller sub-catchments will be available.

Acknowledgements. The authors would like to thank the Khorasan Razavi Regional Water Authority for supplying funding for this $\mathrm{PhD}$ research (Contracted Number KOE-92075). We would further like to thank TAMAB for providing water quality datasets. We also thank the Kerman Graduate University of Advanced Technology for the structural support; and appreciate the classmate for helping with the statistical analyzing the water quality data.

\section{REFERENCES}

[1] Abd El-Kawy, O. R., Rød, J. K., Ismail, H. A., Suliman, A. S. (2011): Land use and land cover change detection in the western Nile delta of Egypt using remote sensing data. Applied Geography 31: 483-494.

[2] Al-Ahmadi, F. S., Hames, A. S. (2009): Comparison of four classification methods to extract land use and land cover from raw satellite images for some remote arid areas, Kingdom of Saudi Arabia. - Journal of King Abdul-Aziz University 20(1): 167-191. 
[3] Chen, J., Lu, J. (2014): Effects of land use, topography and socio-economic factors on river water quality in a mountainous watershed with intensive agricultural production in east China. - PLoS One 9. DOI: 10.1371/journal.pone.0102714.

[4] Dabrowski, J. M., de Klerk, L. P. (2013): An assessment of the impact of different land use activities on water quality in the upper Olifants River catchment. - Water SA 39(2): 231-244.

[5] Dewan, A. M., Yamaguchi, Y. (2009): Land use and land cover change in Greater Dhaka, Bangladesh: using remote sensing to promote sustainable urbanization. - Applied Geography 29: 390-401.

[6] Ding, J., Jiang, Y., Fu, L., Liu, Q., Peng, Q., Kang, M. (2015): Impacts of Land use on surface water quality in a subtropical river basin: a case study of the Dongjiang River Basin, South-eastern China. - Water-Open Access Journal 7: 4427-4445.

[7] Ding, J., Jiang, Y., Liu, Q., Hou, Z., Liao, J., Fu, L., Peng, Q. (2016): Influences of the land use pattern on water quality in low-order streams of the Dongjiang River basin, China: a multi-scale analysis. - Science of the Total Environment 551-552: 205-216.

[8] Du Plessis, A., Harmse, T., Ahmed, F. (2014): Quantifying and predicting the water quality associated with land cover change: a case study of the Blesbok Spruit Catchment, South Africa. - Water 6(10): 2946-2968.

[9] Erdogan, N., Nurlu, E., Guvensen, A., Erdem, U. (2015): Land use/land cover change detection for environmental monitoring in Turkey: a case study in Karaburun Peninsula. Journal of Environmental Protection and Ecology 16: 252-263.

[10] Esterby, S. R. (1996): Review of methods for the detection and estimation of trends with emphasis on water quality applications. - Hydrological Processes 10: 127-149.

[11] Farzamand, A., Arzani, H., Javadi, S. A., Sanadgol, A. A. (2018): Determining the factors affecting rangeland suitability for livestock and wildlife grazing. - Applied Ecology and Environmental Research 17(1): 317-329.

[12] Huang, Z., Han, L., Zeng, L., Xiao, W., Tian, Y. (2016): Effects of land use patterns on stream water quality: a case study of a small-scale watershed in the Three Gorges Reservoir Area, China. - Environmental Science and Pollution Research 23(4): 39433955.

[13] Jensen, J. R. (2015): Introductory Digital Image Processing: A Remote Sensing Perspective. 4rd Ed. - Prentice Hall, Upper Saddle River, NJ.

[14] Joorabian Shooshtari, S. H., Hosseini, S. M., Esmaili-Sari, A., Gholamalifard, M. (2012): Monitoring land cover change, degradation, and restoration of the Hyrcanian forests in northern Iran (1977-2010). - International Journal of Environmental Sciences 3: 10381056. DOI: $10.6088 /$ ijes.2012030133012.

[15] Khoi, D. D., Murayama, Y. (2010): Forecasting areas vulnerable to forest conversion in the Tam Dao national park region, Vietnam. - Remote Sensing 2: 1249-1272.

[16] Kibena, J., Nhapi, I., Gumindoga, W. (2014): Assessing the relationship between water quality parameters and changes in landuse patterns in the Upper Manyame River, Zimbabwe. - Physics and Chemistry of the Earth, Parts A/B/C 67-69(0): 153-163.

[17] Li, Y. L., Liu, K., Li, L., Xu, Z. X. (2012): Relationship of land use/cover on water quality in the Liao River basin, China. - Procedia Environmental Sciences 13: 14841493.

[18] Lunetta, R. S., Elvidge, C. D. (1998): Remote Sensing Change Detection. - Ann Arbor Press, Chelsea, MI.

[19] Maimaitijiang, M., Ghulam, A., Sandoval, J. S. O., Maimaitiyiming, M. (2015): Drivers of land cover and land use changes in St. Louis metropolitan area over the past 40 years characterized by remote sensing and census population data. - International Journal of Applied Earth Observation and Geoinformation Part B 35: 161-174.

[20] Mello, K., Valente, R., Randhir, T., Dos Santos, A., Alberto Vettorazzi, C. (2018): Effects of land use and land cover on water quality of low-order streams in Southeastern Brazil: watershed versus riparian zone. - Catena 167: 130-138. 
[21] Minaei, M., Kainz, W. (2016): Watershed land cover/land use mapping using remote sensing and date mining in Gorganrood, Iran. - International Journal of Geo-Information 5: 57. DOI: 10.3390/ijgi5050057.

[22] Miserendino, M. L., Casaux, R., Archangelsky, M., Di Prinzio, C. Y., Brand, C., Kutschker, A. M. (2011): Assessing land-use effects on water quality, in-stream habitat, riparian ecosystems and biodiversity in Patagonian northwest streams. - Science of the Total Environment 409(3): 612-624.

[23] Monteiro, A. T., Fava, F., Hiltbrunner, E., Marianna, G. D., Bocchi, S. (2011): Assessment of land cover changes and spatial drivers behind loss of permanent meadows in the lowlands of Italian Alps. - Landscape and Urban Planning 100: 287-294.

[24] Namugize, J., Jewitt, G., Graham, M. (2018): Effects of land use and land cover changes on water quality in the uMngeni river catchment, South Africa. - Physics and Chemistry of the Earth, Parts A/B/C 105: 247-264.

[25] Pratt, B., Chang, H. (2012): Effects of land cover, topography, and built structure on seasonal water quality at multiple spatial scales. - Journal of Hazardous Materials 209: 48-58.

[26] Rafiee, R., Mahiny, A. S., Khorasani, N. (2009): Assessment of changes in urban green spaces of Mashad city using satellite data. - International Journal of Applied Earth Observation and Geoinformation 11: 431-438.

[27] Schulz, J. J., Cayuela, C., Echeverria, C., Salas, J., Rey Benayas, J. M. (2010): Monitoring land cover change of the dryland forest landscape of Central Chile 19752008. - Applied Geography 30: 436-447.

[28] Shalaby, A., Tateishi, A. (2007): Remote sensing and GIS for mapping and monitoring land cover and landuse changes in the north-western coastal zone of Egypt. - Applied Geography 27: 28-41.

[29] Sheikhy Narany, T., Zaharin Aris, A., Sefie, A., Keesstra, S. (2017): Detecting and predicting the impact of land use changes on groundwater quality, a case study in Northern Kelantan, Malaysia. - Science of the Total Environment 599-600: 844-853.

[30] Shi, P., Zhang, Y., Li, Z., Li, P., Xu, G. (2017): Influence of land use and land cover patterns on seasonal water quality at multi-spatial scales. - Catena 151: 182-190.

[31] Tong, S. T. Y. (1990): The hydrologic effects of urban land use: a case study of the Little Miami River Basin. - Landscape \& Urban Planning 19: 99-105.

[32] Tong, S. T. Y., Chen, W. (2002): Modelling the relationship between land use and surface water quality. - Journal of Environmental Management 66: 377-393.

[33] Vörösmarty, C. J., McIntyre, P. B., Gessner, M. O., Dudgeon, D., Prusevich, A., Green, P., Glidden, S., Bunn, S. E., Sullivan, C. A., Liermann, C. R. (2010): Global threats to human water security and river biodiversity. - Nature 467: 555-561.

[34] Walling, D. E., Fang, D. (2003): Recent trends in the suspended sediment loads of the world's rivers. - Global and Planetary Change 39: 111-126.

[35] Wan, R., Cai, S., Li, H., Yang, G., Li, Z., Nie, X. (2014): Inferring land use and land cover impact on stream water quality using a Bayesian hierarchical modeling approach in the Xitiaoxi River Watershed, China. - Journal of Environmental Management 133(0): 111.

[36] Wayland, K. G., Hyndman, D. W., Boutt, D., Pijanowski, B. C., Long, D. T. (2002): Modeling the impact of historical land uses on surface-water quality using groundwater flow and solute-transport models. - Lakes \& Reservoirs: Research and Management 7: 189-199.

[37] Withers, P. J., Jarvie, H. P. (2008): Delivery and cycling of phosphorus in rivers: a review. - Science of the Total Environment 400: 379-395.

[38] Worrall, F., Burt, T. P. (1999): The impact of land-use change on water quality at the catchment scale: the use of export coefficient and structural models. - Hydrology 221: $75-90$. 
[39] Wu, Q., Li, H., Wang, R., Paulussen, J., He, Y., Wang, M., Wang, B., Wang, Z. (2006): Monitoring and predicting land use change in Beijing using remote sensing and GIS. Landscape and Urban Planning 78: 322-333.

[40] Yuan, E., Kali Sawaya, K. E., Loeffelholz, B. C., Bauer, M. E. (2005): Land cover classification and change analysis of the Twin Cities (Minnesota) Metropolitan Area by multi-temporal Landsat remote sensing. - Remote Sensing Environment 98: 317-328.

[41] Zamani, M., Sadoddin, A., Garizi, A. Z. (2013): Assessing land cover/land use change and its impacts on surface water quality in the Ziarat catchment, Golestan Province-Iran. - Hydrology Current Research - Open Access Journal 4: 1-5.

[42] Zhou, T., Wu, J., Peng, S. (2012): Assessing the effects of landscape pattern on river water quality at multiple scales: a case study of the Dongjiang River watershed, China. Ecological Indicators 23: 166-175. 